\title{
LIÇÕES PARA A HISTÓRIA DAS \\ CIÊNCIAS NO BRASIL: \\ INSTITUTO PASTEUR DE SÃO PAULO
}

\author{
LESSONS FOR THE HISTORY \\ OF SCIENCE IN BRAZIL: \\ SÃO PAULO'S PASTEUR INSTITUTE
}

Maria Alice Rosa Ribeiro*

RIBEIRO, M. A. R.: 'Lessons for the history of science in Brazil: São Paulo's Pasteur Institute'. História, Ciências, Sauide - Manguinhos, III (3):467-484, Nov. 1996-Feb. 1997.

The article highlights the role played by São Paulo's Pasteur Institute (1903-16) in the development of microbiological science in Brazil and in the emergence of a pharmaceutical industry owned by Brazilian capital.

KEYWORDS: history of science, economic history, public bealth, pharmaceutical industry, São Paulo, Brazil/Brasil.

\begin{abstract}
*Professora do Departamento de Economia da Faculdade de Ciências e Letras da Universidade Estadual Paulista (FCL/ Unesp/Araraquara). A autora destaca que foram fundamentais as sugestões do prof. Luiz Antonio de Castro Santos à versão preliminar.

Rua das Camélias, 750 Chácara Primavera 13087-650 Campinas - SP

1 Este artigo foi escrito a partir da leitura de Ciência e sanide na terra dos bandeirantes: a trajetória do Instiluto Pasteur de São Paulo no periodo 1903-16 (Teixeira, 1995).
\end{abstract}

Muitos de nós conhecem o casarão situado na av. Paulista, um exemplar ainda preservado da arquitetura paulistana do início do século, mas poucos sabem que aquele prédio, identificado por uma placa - Instituto Pasteur - abrigou, de fato, um grupo de cientistas preocupados em desenvolver a nova ciência biológica, a microbiologia, o estudo das bactérias e de outros microrganismos nas doenças dos seres humanos e dos animais. ${ }^{1}$ O Instituto Pasteur foi criado, em 1903, para fornecer o tratamento anti-rábico e produzir a vacina contra a raiva, porém, ele não irá se restringir a este objetivo. Seguindo os passos do seu congênere francês, voltou-se para a pesquisa científica, para a produção de conhecimento científico, para a divulgação do método de investigação bacteriológico, para a formação de cientistas dentro da concepção microbiana da doença e para a elaboração de produtos - soros e vacinas - destinados a prevenir e debelar doenças. Este artigo pretende tratar deste instituto, do seu papel na formação da ciência no Brasil, das dificuldades de se fazer ciência num país de tão grandes contrastes e do surgimento da indústria farmacêutica. A microbiologia data do último quartel do século XIX e surgiu no contexto histórico no qual se relacionam vários elementos, desde os 
aperfeiçoamentos dos instrumentos de observação, graças aos conhecimentos da física ótica, a derrocada das teorias da geração espontânea, a importância crescente do estudo de um mundo biológico constituído por organismos inferiores, os micróbios, até a consolidação de uma prática higienista voltada para a intervenção na sociedade urbano-industrial. Por volta de 1854, Pasteur iniciou suas pesquisas, como químico, preocupado com problemas na fermentação de cervejas e vinhos. Ele verificou que a contaminação nos processos de fermentação estava associada à presença de outros microrganismos, além daqueles específicos à fermentação adequada para a produção dessas bebidas e recomendou o aquecimento a uma certa temperatura para evitar a contaminação. Dos estudos ligados à indústria de bebidas, Pasteur aproximou-se das pesquisas sobre doenças nos homens e nos animais e seus estudos voltaramse para a identificação de microrganismos relacionados às moléstias. Depois de vinte anos de estudos, Pasteur concebe que as doenças contagiosas são devidas à ação de germes microbianos infecciosos, que penetram no organismo, e busca identificar profiláticos capazes de tornar os organismos imunes à ação dos micróbios. Seus estudos e pesquisas influenciaram cientistas na identificação de bactérias, na busca de métodos e técnicas de obtenção de culturas bacterianas e na determinação do papel específico dos micróbios nas doenças.

$\mathrm{Na}$ década de 1870 , a microbiologia consolida-se como uma nova disciplina científica e define normas para a pesquisa científica, as quais sistematizam os procedimentos nos seguintes passos: a demonstração da presença do microrganismo; o seu isolamento; a obtenção da cultura artificial ou laboratorial do microrganismo e a inoculação de animais de laboratório.

Pasteur dedicou-se à identificação de microrganismos relacionados às doenças e à elaboração de profiláticos e terapêuticos para prevenilas ou curá-las. Todo o esforço para a produção de profiláticos era feito por meio de experiências e testes em animais. Pasteur hesitou por muito tempo em aplicar suas vacinas no homem. Até que, em 1885, um jovem alsaciano mordido por um cão raivoso apareceu no seu laboratório e, diante da condenação do jovem à morte certa, a vacina foi aplicada pela primeira vez no ser humano. Com o êxito desta aplicação, as vacinações anti-rábicas começaram a ser empregadas no tratamento da raiva no homem. Três anos mais tarde, Pasteur fundou a instituição que será um dos modelos organizacionais para o desenvolvimento da pesquisa bacteriológica e do ensino da microbiologia e para a produção de profiláticos e terapêuticos - vacinas e soros -, o Instituto Pasteur de Paris.

A microbiologia chega ao Brasil na década de 1880, por meio de alguns estudiosos como Domingos José Freire Jr. (1842-99), professor de química orgânica e biologia da Faculdade de Medicina do Rio de Janeiro, que realizou a primeira tentativa de identi- 
. 2 Ver Rheinboldt, (1956, pp. 9-93). Possivelmente, o imperador foi influenciado por seu tutor, José Bonifácio de Andrada e Silva (1763-1838), cujo nome está ligado à descoberta de um novo metal, o lítio, em 1818. O Patriarca da Independência do Brasil, entre outros títulos, ostenta o de Patriarca dos Químicos Brasileiros. Em 1790, José Bonifácio aperfeiçoou-se em química, engenharia de minas $e$ metalurgia, a fim cle introduzir estes conhecimentos em Portugal e na Colônia. Ficou dois anos em Paris, onde freqüientou o curso de química de J. A. Chaptal e A. F. Foucroy. Depois seguiu para a Saxônia, onde freqüentou por três anos o curso da Real Academia de Minas de Freiburg, tendo sido contemporâneo de Alexander von Humboldt e Leopoldo von Buch. Fez estudos exploratórios nos distritos mineiros da Alemanha, Áustria, Suécia e Inglaterra durante a década de 1890. Na Suécia, descobriu, nas minas de Uto, dois novos minerais, sendo que um deles foi o lítio. Escreveu trabalhos científicos considerados de valor para a época. ficação do micróbio da febre amarela e preparou uma vacina contra esta enfermidade; João Batista de Lacerda (1846-1915), pesquisador do Museu Nacional, que iniciou pesquisas neste no campo do conhecimento, as quais resultaram na descoberta de uma vacina contra a peste da manqueira ou carbúnculo sintomático, por volta de 1895; Adolfo Lutz (1855-1940), médico e diretor do Instituto Bacteriológico de São Paulo, que identificou epidemias como a febre tifóide, a cólera, entre outras, em 1893-95. O interesse do imperador d. Pedro II pelas novidades científicas e tecnológicas que surgiam na Europa também contribuiu para a introdução de estudos científicos baseados na nova ciência - o próprio imperador fez uma contribuição vultosa para a criação do Instituto Pasteur de Paris. ${ }^{2}$ Esta época também marcou o momento de revigoramento da Faculdade de Medicina do Rio de Janeiro, com a gestão do visconde de Sabóia (1881-89), novo currículo e novos laboratórios e clínicas. $\mathrm{E}$ em 1888, nove meses antes da inauguração do Instituto Pasteur de Paris, a cidade do Rio de Janeiro ganhou o primeiro Instituto Pasteur, totalmente montado com aparelhagem importada para o desenvolvimento da pesquisa bacteriológica e para a produção da vacina antirábica. O instituto foi criado anexo à Santa Casa da Misericórdia e sob a direção do lente da cadeira de química mineral da Faculdade de Medicina, Augusto Ferreira dos Santos, que alguns anos antes fora enviado pelo imperador à Europa com o objetivo de estudar microbiologia e as técnicas desenvolvidas por Pasteur. O instituto restringiu sua produção à elaboração e aplicação da vacina e pouco contribuiu para o desenvolvimento da microbiologia, por meio de novas pesquisas e da formação de novos cientistas. Do pólo irradiador da pesquisa bacteriológica, proposto inicialmente, o instituto converteu-se, na realidade, em serviço técnicoassistencial de rotina.

Cabe ressaltar que os institutos Pasteur criados no país - no Rio de Janeiro (1888), no Recife (1899), em São Paulo (1903), em Juiz de Fora (1908), em Porto Alegre (1910), em Santa Catarina (1912) — não tinham qualquer ligação institucional com o Instituto Pasteur de Paris e nem com as filiais deste espalhadas pelas colônias francesas do Extremo Oriente (Saigon, Hha Trang, Hanói, Hué, Bangcoc, Phnom Penh e Chengtu) e da África (Argel e Casablanca), os quais desempenharam papel expressivo na consolidação da colonização francesa e no desenvolvimento de trabalhos de pesquisa sobre doenças tropicais do homem e dos animais.

Os institutos Pasteur brasileiros dedicaram-se com exclusividade à produção e aplicação da vacina anti-rábica, sendo identificados somente como os prestadores de tratamento preventivo e curativo da raiva. À exceção do Instituto Pasteur de São Paulo, que se aproximou do modelo organizacional estabelecido no Instituto 
${ }^{3} \mathrm{O}$ argumento de Teixeira (1995, pp. 21-2), de que a subordinação do Instituto Pasteur do Rio de Janeiro à Santa Casa da Misericórdia e não à Faculdade de Medicina do Rio de Janeiro marcou seu caráter clínico e não-científico, pareceu-me insuficiente. Outro instituto estava ligado à academia, o de Porto Alegre, e nem por isso demonstrou preocupação científica mais ampla, como a que se observa no Instituto Pasteur de São Paulo.
Pasteur de Paris, diversificando suas atividades, para cobrir as três principais áreas de atividade para o desenvolvimento da microbiologia: a investigação bacteriológica, o ensino e a produção de imunizantes. Além disso, todos os institutos, à exceção do de São Paulo, estavam ligados a uma instituição maior, como a Santa Casa da Misericórdia (Rio de Janeiro, Recife) e a Faculdade de Medicina (Porto Alegre), e assim formavam mais uma unidadeanexa de prestação de serviço de assistência às vítimas da raiva do que um centro de pesquisa e desenvolvimento da microbiologia. Mesmo a ligação com a Faculdade de Medicina, cujo caráter acadêmico poderia influenciar os institutos na direção do desenvolvimento de pesquisas científicas, parece não ter conseguido retirar deles o caráter exclusivo de fornecedores do tratamento contra a raiva. É difícil identificar o que levou os institutos a assumirem este caráter restrito, fugindo ao modelo de organização científica do Instituto Pasteur de Paris. ${ }^{3}$ Entretanto, a pergunta mais correta seria por que o Instituto Pasteur de São Paulo fugiu daquela característica presente em todos? Afinal, o Instituto Pasteur de São Paulo foi o que seguiu o caminho distinto!

Para aproximar-se de uma resposta, é preciso seguir a distinta trajetória percorrida pelo Instituto Pasteur de São Paulo. O instituto resultou da iniciativa de um grupo de médicos interessados no desenvolvimento da medicina laboratorial, por meio das atividades de pesquisa bacteriológica, do ensino da microbiologia e da produção de imunizantes. Este projeto foi seguido à risca, em especial, durante a gestão do dr. Antonio Carini, quando o instituto trilhou o caminho da pesquisa bacteriológica, buscando as causas de moléstias infecciosas; nesta ocasião ele produziu ciência e elaborou novos produtos profiláticos e terapêuticos.

$\mathrm{O}$ instituto nasceu independente, sem vínculo institucional, $\mathrm{e}$ seu compromisso era com o grupo de médicos e de apoiadores que o idealizou. O grupo soube escolher um 'nicho' não preenchido pelas instituições que formavam a estrutura do Serviço Sanitário, criadas pelo estado de São Paulo no final do século: não havia nenhuma instituição que prestasse serviço de tratamento contra a raiva e a porta de entrada estava aberta. Mas seus idealizadores eram mais ambiciosos, não pretendiam se restringir à reprodução da técnica de preparação da vacina, já de domínio público. Eles desejavam transformar a instituição num centro de pesquisa e desenvolvimento da microbiologia. O que, de fato, deve ter contribuído para esse objetivo era o efervescente ambiente cultural por que passava a cidade de São Paulo desde a proclamação da República. A forma de regime republicano e, em especial, o federalismo trouxeram para São Paulo a autonomia e a maturidade administrativa de que tanto precisava como principal produtor da riqueza nacional. Uma série de instituições estatais e privadas, de 
cunho científico, foram criadas no período: o Serviço Sanitário, a Sociedade de Medicina e Cirurgia, publicações médicas, como, por exemplo, os Anais da Sociedade de Medicina e Cirurgia e a Revista Médica de São Paulo; ou seja, havia um movimento de aglutinação dos interesses científicos ligados à medicina e à saúde pública estimulado, possivelmente, pela nova ciência (Ribeiro, 1993).

Apesar deste movimento, profissionais e cientistas ressentiamse da falta da Faculdade de Medicina, local verdadeiramente adequado para a discussão das questões científicas. $\mathrm{Na}$ verdade, a criação do Instituto Pasteur abria um espaço de discussão, de ensino e de investigação científica, preenchendo, em parte, a falta que a Faculdade de Medicina fazia numa sociedade que passava por profundas transformações políticas, econômicas, culturais e científicas. Não é por acaso que, quando a Faculdade de Medicina foi criada, os cursos de microbiologia cessaram de ser ministrados no Instituto Pasteur e seus principais cientistas, Antonio Carini e Ulisses Paranhos, foram convidados a lecionar na faculdade (Teixeira, 1995, pp. 77, 117-21).

$O$ instituto notabilizou-se na preparação da vacina anti-rábica e no tratamento gratuito da doença, tornou-se um ponto de vacinação contra a varíola (utilizando a vacina preparada pelo Instituto Vacinogênico) e dedicou-se à produção de outros imunizantes, tais como os soros antidiftérico e antitetânico e, na área veterinária, o soro anticarbunculoso, a vacina contra o carbúnculo sintomático e hemático, a tuberculina e a maleína usados no diagnóstico da tuberculose bovina e do mormo eqüino.

A preparação de novas substâncias relevantes para a saúde pública e para uso veterinário era prevista nos estatutos da instituição. A única restrição era à fabricação de produtos, medicamentos, vacinas e soros que concorressem com aqueles produzidos pelas instituições públicas paulistas; portanto, o soro antipestoso permanecia sendo produzido, com exclusividade, pelo Instituto Butantã.

$\mathrm{Na}$ área do ensino, o instituto ministrou cursos de bacteriologia geral, técnica bacteriológica, bacteriologia e microscopia aplicadas à clínica e à higiene, além de um curso de inspeção de alimentos.

Por fim, na área de pesquisa, a proposta era o estudo de moléstias tropicais, endêmicas e epidêmicas, e a divulgação dos trabalhos científicos no órgão oficial do instituto - a revista trimestral. $\mathrm{O}$ trabalho de pesquisa previsto estava dirigido para a pesquisa aplicada à solução de problemas da saúde pública $e$ veterinários, semelhantemente ao Instituto Pasteur de Paris.

Não se pode esquecer que o grande salto no reconhecimento mundial do Instituto Pasteur de Paris ocorreu devido ao desenvolvimento de pesquisa aplicada aos problemas de saúde pública. 
${ }^{4}$ Ivo Bandi regressou à Itália, onde a Universidade de Bolonha the outorgou a caitedra de higiene e bacteriologia, em 1905 (ver Lacaz, 1989, pp. 41-2).

${ }^{5}$ Antonio Carini (18721950) era diplomado pela Faculdade de Medicina de Pavia e defencleu, em Berna, sua tese de cloutoramento sobre vacinas anti-rábicas (Lacaz, op., cit,, p. 41).
Em 1894, quando seu cientista Émile Roux comunicou a descoberta do soro antidiftérico, o instituto passou a ser o grande centro de produção deste soro, o que lhe trouxe benefícios econômicos, além de permitir uma ligação mais estreita com a saúde pública, dada a maior incidência da difteria do que da raiva. Os vínculos com a saúde pública reforçavam-se desde a descoberta do bacilo diftérico por Roux e Yersin, em 1888, e os estudos sobre fagocitose e processos inflamatórios por Metchnikoff realizados entre 18881900. Tornaram-se mais fortes com a descoberta do tratamento da difteria, por meio do soro desenvolvido por Roux, Martin e Chaillou, e com a identificação e isolamento do bacilo da peste por Yersin, em Hong Kong, em 1894. Graças ao reconhecimento do trabalho científico desenvolvido pelo instituto, foi possível abrir novas subscrições públicas, o que permitiu a obtenção de recursos para não somente ampliar as instalações, como, também, construir o Hospital Pasteur e o Instituto de Química Biológica e outras unidades (idem, ibidem, p. 53).

Inspirado neste modelo organizacional de produzir ciência vinculada à saúde pública, à pecuária e à agricultura, o Instituto Pasteur de São Paulo viu concretizar o ideal na gestão do seu segundo diretor, Antonio Carini, que substituiu Ivo Bandi devido às divergências deste último com Emílio Ribas, diretor do Serviço Sanitário. Não que Ivo Bandi, competente bacteriologista, fosse incapaz de fazê-lo, mas ele não dispôs de tempo suficiente. ${ }^{4}$

Antonio Carini, bacteriologista italiano e diretor do Instituto de Bacteriologia, Soroterapia e Moléstias Infecciosas de Berna, na Suíça, aceitou o cargo de diretor do instituto em 1906.5 Carini veio para São Paulo imbuído de um enorme espírito de pesquisador interessado em avançar o conhecimento em microbiologia. O fascínio pelos trópicos, em especial pela América Latina, tão marcante nos cientistas do século XIX, manifestava-se em Carini, que enxergava a região como um imenso reservatório para o estudo de doenças. O reconhecimento científico mundial obtido pelos cientistas que estiveram nos trópicos e as possibilidades de encontrar solução para as doenças no desenvolvimento da microbiologia influenciaram sua decisão de trocar o consolidado instituto suíço pelo recém-criado instituto de São Paulo, que não passava de uma promessa.

Com seu entusiasmo, Carini reuniu um grupo de cientistas que iria conferir visibilidade à instituição devido às suas articulações com o desenvolvimento da atividade econômica do estado e do país, com os problemas da saúde pública e com a formação de uma nova geração de cientistas. Além disso, o instituto preocupavase em divulgar os trabalhos científicos desenvolvidos nos seus laboratórios e em participar os debates na Sociedade de Medicina e Cirurgia e na Sociedade Científica de São Paulo. Faziam parte do 
grupo: Ulisses Paranhos, Eduardo Marques (cientista formado no Instituto de Manguinhos) e Francisco Mastrangioli (químico contratado para dirigir a seção de Química).

O Instituto Pasteur de São Paulo seguiu caminhos diferentes por influência das condições que se manifestaram nos anos finais do século XIX. A prosperidade econômica de São Paulo, a mudança de regime político, a autonomia administrativa reforçaram-se, mutuamente, e contribuíram para criar um clima favorável à organização de instituições científicas. Foi neste contexto que ocorreu o encontro da elite paulista, que se mostrava receptiva a projetos de natureza científica, com um grupo de cientistas dispostos a ampliar e diversificar o campo de penetração do pensamento científico e da nova abordagem dos problemas biomédicos. Para se ter uma idéia deste esforço de difusão da ciência, é importante conhecer um pouco mais os trabalhos desenvolvidos pelo Instituto Pasteur de São Paulo.

Não resta dúvida de que os cursos ministrados por este grupo de cientistas contribuíram para divulgar a microbiologia e a técnica bacteriológica. Eles constavam de uma parte teórica e outra prática e nesta última eram tratados aspectos da microscopia dos grupos de microrganismos patológicos, das técnicas de elaboração de exames bacteriológicos e de diversas doenças infecciosas. Foram realizados em 1907, 1909 e 1911 e eram os únicos cursos disponíveis para a formação de pessoal especializado em questões da medicina experimental e veterinária e em saúde pública, em São Paulo.

Quanto à produção de profiláticos e terapêuticos, percebe-se a predominância da produção de medicamentos de uso veterinário. $\mathrm{Na}$ Exposição de Zootécnica de 1906, o instituto expôs seus produtos para divulgação junto ao principal mercado consumidor: os agricultores e pecuaristas paulistas. A lista de produtos incluía vacinas contra carbúnculo sintomático (peste da manqueira) e contra carbúnculo hemático, soro anticarbunculoso e antitetânico, tuberculina de Koch para diagnóstico da tuberculose bovina, maleína para diagnóstico do mormo do gado e o vírus contagioso para destruição de ratos e camundongos. Em 1914, a produção diversificou-se para incluir vacinas antitíficas, vacinas Rwight, soro antiestreptocócico polivalente e soro antidiftérico de uso veterinário. Os medicamentos de uso humano progrediram na área de produtos opoterápicos, como soro da veia renal da cabra, indicado no tratamento de nefrites; soro normal de cavalo, indicado para hemorragias, anemias e moléstias na composição do sangue; tuberculinas, destinadas ao diagnóstico precoce da tuberculose em adultos e crianças; a tuberculina de Berameck, indicada para o tratamento da tuberculose humana. 
A seção de bacteriologia elaborava reações de Wassermann para diagnóstico da sífilis e a reação de Widal para diagnóstico da febre tifóide, e a seção de química elaborava soluções medicamentosas esterilizadas, tais como cocaína, morfina etc. Da lista de produtos, apenas dois tiveram sua produção regular e geraram, de fato, renda para o instituto: as vacinas contra o carbúnculo sintomático $\mathrm{e}$ as reações de Wassermann para o diagnóstico da sífilis (idem, ibidem, p. 78).

Na produção de medicamentos, o problema enfrentado pelo instituto dizia respeito à concorrência com outros produtores e à dificuldade de estabelecer um esquema de comercialização, propaganda e canais de distribuição. Como o estado não se tornou seu principal cliente, como foi o caso do Instituto Pasteur de Paris, o que por si só garantiria uma renda regular, ele dependia ainda mais de um intenso trabalho de comercialização. As dificuldades parecem residir neste ponto. No caso da vacina contra o carbúnculo sintomático, existiam no mercado vários produtores: o Instituto de Manguinhos, cuja vacina líquida era a mais conhecida, a vacina de Thomas e a vacina do Parke-Davis. Para elevar a renda e driblar a concorrência, o próprio Instituto Pasteur passou a ser o principal revendedor das vacinas dos laboratórios estrangeiros concorrentes.

Já em 1911, a renda dos exames de diagnóstico da sífilis Wassermann era a principal parcela da receita gerada. Cabe ressaltar que Carini foi um dos primeiros médicos no país a introduzir o exame de preventivo da sífilis, que era de extrema importância para a saúde pública da época. Em 1909, foram feitas apenas três reações; já em 1911, quando o serviço era mais conhecido do público, foram feitas 1.580 (idem, ibidem, p. 81).

A seção de Química, chefiada por Francisco Mastrangioli, também contribuiu para melhorar as condições do autofinanciamento do instituto, produzindo substâncias químicas de uso terapêutico vendidas para as indústrias farmacêuticas, tais como preparação da morfina, da cocaína, da esparteína, da cafeína, do óleo canforado, da estricnina, do cacodilato de sódio e de ferro, do éter sulfúrico. Esta seção, entre 1907 e 1909, chegou a fazer cerca de quarenta preparações, elaborava análises químicas de alimentos para a indústria produtora de alimentos e fazia exames médicos para clínicos da cidade. Porém, ela logo foi desativada e o químico, demitido em 1909. O problema enfrentado por esta seção também foi a dificuldade de comercialização dos seus produtos e serviços. Sua manutenção dependeria de um estreitamento nas relações com o governo municipal, na forma da regulamentação de um contrato para prestar serviço de fiscalização e análise química dos alimentos vendidos na capital, em especial do leite, que nunca chegou a ser oficializado pela Câmara Municipal ou pelo prefeito. 
A consolidação de uma instituição depende da importância que a comunidade lhe atribui na solução dos problemas enfrentados, do reconhecimento da relevância do trabalho científico desenvolvido e do interesse dos diversos segmentos sociais e profissionais pelas suas atividades. Teoricamente, essa é uma forma de avaliar uma instituição, mas ela não pode ser absoluta, pois depende ainda do grau de desenvolvimento cultural e da riqueza material de uma sociedade. Quando as disparidades culturais e as desigualdades de riqueza são tremendas, não há como fazer chegar à sociedade, como um todo, as contribuições da instituição de pesquisa científica e sua consolidação e reconhecimento ficam prejudicados. Essa parece ser a diferença entre o Instituto Pasteur de São Paulo e o de Paris, o último obteve reconhecimento de toda comunidade, o que viabilizou sua consolidação por meio de subscrições, de doações e de legados deixados para financiar a pesquisa realizada e percebida como necessária por uma sociedade culta e rica.

O reconhecimento do Instituto Pasteur de São Paulo como local onde os profissionais da área biomédica poderiam realizar investigações, utilizando suas instalações e seus recursos laboratoriais, foi pequeno. A pesquisa no instituto foi realizada exclusivamente pelo seu próprio quadro de pesquisadores (três a quatro), embora seus laboratórios estivessem abertos a outros pesquisadores, médicos e estudantes de medicina.

Apesar de o instituto se propor a publicar uma revista própria, isto nunca chegou a ser concretizado. Isto, entretanto, não impediu que os seus pesquisadores divulgassem suas pesquisas; de fato, segundo o levantamento de Teixeira (ibidem, p. 85), eles publicaram cerca de três vezes mais que os pesquisadores do Butantã no período de 1903-16.

As pesquisas em medicina humana versaram sobre variados assuntos do conhecimento biomédico, porém, se alguma convergência pode ser vislumbrada, está nas pesquisas voltadas para problemas de saúde pública, tais como úlcera de Bauru, sífilis, ancilostomose, beribéri, malária, doença de Chagas, alastrim e lepra. Aqui é possível perceber o maior reconhecimento conferido ao Instituto Pasteur, embora se restringisse a uma pequena parcela da sociedade, constituída por profissionais da área médica e correlatas.

Neste campo de investigação, além de Carini, destacou-se o segundo nome do instituto, o dr. Ulisses Paranhos, com seus estudos sobre a lepra, a ancilostomose e outras moléstias. O estudo sobre a úlcera de Bauru, forma especial de leishmaniose, feito juntamente com Carini e Adolfo Lindemberg, médico da Santa Casa da Misericórdia, resultou no estabelecimento dos procedimentos para a realização do diagnóstico laboratorial da 
doença e provocou o interesse na realização de pesquisas sobre substâncias empregadas no tratamento, as quais foram desenvolvidas pelo cientista Gaspar Viana, do Instituto de Manguinhos (idem, ibidem, p. 95).

O estudo sobre a úlcera de Bauru mostrou que o trabalho de cooperação de cientistas de diferentes instituições científicas e hospitalares - no caso, o Instituto Pasteur de São Paulo, a Santa Casa da Misericórdia de São Paulo e o Instituto de Manguinhos potencializava os resultados das investigações. A mesma cooperação verificou-se quando Carini e Jesuíno Maciel mapearam a distribuição da ocorrência da doença de Chagas no estado de São Paulo, em um trabalho que contribuiu para comprovar que a doença não se limitava a uma determinada zona geográfica. No plano internacional, a cooperação científica entre o Instituto Pasteur de São Paulo e o de Paris foi responsável pela identificação de um novo parasita. Carini enviou preparações dos cistos retirados dos pulmões de cobaias supostamente infectadas por Tripanosoma lewisi para o Instituto Pasteur de Paris, onde a análise constatou a presença de um novo parasita: não o Tripanosoma lewisi, como imaginava Carini, mas o parasita Pneumocisti carini, nome dado em homenagem ao cientista que o havia descoberto, mas não identificado (idem, ibidem, p. 97). Hoje, este parasita é muito conhecido por provocar a doença oportunista, tuberculose pulmonar, entre os doentes de Aids.

A controvérsia não significa, necessariamente, ausência de cooperação e, a não ser que envolva a vaidade e outras fraquezas humanas, pode convergir para um maior conhecimento científico. As disputas por acertos nos diagnósticos, teoricamente, devem ser entendidas como benéficas para o desenvolvimento científico, embora, na prática, elas quase sempre provoquem rusgas entre os cientistas. Este foi o caso de Ribas/Serviço Sanitário versus Carini na discussão do alastrim: um não aceitava o diagnóstico do outro - o primeiro, com base no diagnóstico clínico, o segundo, com base no diagnóstico bacteriológico/laboratorial — e o resultado não poderia ser outro senão prejuízo para a saúde pública. Outra disputa ocorreu no caso da ancilostomose entre Ribas/Serviço Sanitário versus Carini quanto à melhor forma de atacar a moléstia, que atingia milhares de paulistas do interior do estado: brochuras com conselhos médicos distribuídas à população, defendidas pelo Serviço Sanitário, versus timol, defendido por Carini - novamente a perda foi da saúde pública (idem, ibidem, pp. 101-5; Ribeiro, 1993, pp. 188-96). Nos dois casos, observa-se que a combinação das soluções preconizadas, pois elas não eram excludentes, poderia contribuir para a melhoria da saúde pública.

As pesquisas no campo da veterinária foram orientadas para a área da parasitologia, protozoologia e micologia. Nesse campo, 
percebe-se que o reconhecimento do instituto extrapolou os limites das instituições científicas e dos profissionais da área médica, chegando a se manifestar nas associações dos produtores rurais, principalmente a Sociedade de Agricultura. Apesar deste reconhecimento, a entidade de classe nunca contribuiu de forma decisiva para a realização das pesquisas, mesmo quando o instituto mais necessitava de recursos. Carini era uma das maiores autoridades em assuntos veterinários e estimulou a pesquisa sobre algumas zoonoses que atacavam o gado bovino e eqüino no estado de São Paulo, dentre elas o carbúnculo sintomático, peste da manqueira, a piroplasmose bovina, a osteoporose do cavalo, cara inchada, a peste de coçar, o garrotilho dos porcos, a febre aftosa, a toxoplasmose e outras. Tratou de solucionar a mortalidade de bezerros de raça, recém-chegados a São Paulo, identificando a moléstia como sendo piroplasmose bovina, vulgarmente conhecida como tristeza dos bovinos, e determinou o tratamento à base de um composto de arsênico e extinção dos carrapatos vetores da moléstia. Carini fez relevantes contribuições para a ciência, como, por exemplo, ao produzir o primeiro relato sobre a raiva transmitida pelo morcego ao gado (Gambeta, 1982, p. 91; Lacaz, 1989, pp. 85-7).

O Instituto Pasteur fornecia consultorias aos criadores de gado de São Paulo. Carlos Botelho, secretário da Agricultura (1904-08) e grande agricultor e pecuarista, embora prestigiasse o instituto e tivesse, inclusive, participado de um de seus cursos, manifestavase favorável à criação de um centro de pesquisas veterinárias pelo próprio estado, o que denota uma falta de entrosamento entre as atividades a serem desenvolvidas pelo estado e pela iniciativa privada. Mesmo a criação do Posto de Zootécnico mostrou-se insuficiente, dados os problemas dos criadores. Por vários anos, as atividades do instituto supriram a falta de uma instituição pública de pesquisa veterinária, uma vez que o Instituto Butantã dedicava-se ao estudo de zoonoses, enquanto transmissoras de moléstias ao homem. Em 1917, a Secretaria da Agricultura criou o Instituto de Veterinária, o qual recebia orientação técnica do Instituto Butantã. Porém, o Instituto de Veterinária parece não ter tido êxito e logo foi desativado.

Somente em 1925-26, a idéia da criação de um instituto que estudasse os problemas da criação animal concretizou-se com o Instituto Biológico. Este foi, finalmente, criado em 1927, sendo designado diretor Arthur Neiva, que permaneceu no cargo até 1933, sendo então substituído, oficialmente, por Henrique da Rocha Lima. Sob a direção do último, o Instituto Biológico tornouse um centro de pesquisa e de ciência aplicada à solução dos problemas que atingiam a agricultura e a criação de animais. Promovia a defesa agrícola e animal, por meio de campanhas 
${ }^{6}$ Sobre os cursos médicos, ver Nadai (1981) e Faculdade de Medicina da Universidade de São Paulo (1991). Em 1934, a Faculdade de Medicina e Cirurgia passou a integrar a Universidade de São Paulo. junto aos proprietários rurais, de respostas às consultas feitas pelos produtores rurais, da distribuição de folhetos explicativos e da publicação da revista O Biológico. No controle biológico das pragas, a identificação dos inimigos naturais dos fungos, parasitas e insetos orientava as campanhas de defesa vegetal. Na defesa animal, o instituto dedicava-se à fabricação de vacinas preventivas e soros, muitos dos quais constavam da lista de produtos fabricados pelo antigo Instituto Pasteur, tais como vacinas contra carbúnculo sintomático e hemático, tuberculina de Koch, para diagnóstico da tuberculose bovina, e vacina antitetânica. Além destas funções, o Instituto Biológico organizava campanhas contra formigas, cupins e pragas que prejudicavam a lavoura e cursos práticos sobre as pesquisas realizadas. Duas seções compunham o instituto: a Divisão Animal, chefiada por Henrique da Rocha Lima, e a Divisão Vegetal, chefiada por Adalberto de Queiroz Telles (O Biológico, 1977, 1984; Dantes, 1979-80, p. 362).

O declínio do Instituto Pasteur está associado, segundo Teixeira (1995), à centralização das atividades sanitárias nas instituições estatais, estaduais e municipais; à consolidação das pesquisas no Instituto Butantã; ao aumento da incidência de raiva em São Paulo, que provocou desconfiança no trabalho do instituto, e à ameaça do Serviço Sanitário de criar seu próprio serviço de tratamento anti-rábico no Instituto Bacteriológico. Porém, mesmo que a pesquisa se consolidasse nas instituições públicas, isto não impedia que outras instituições tivessem se voltado para a realização da pesquisa científica, mesmo porque a pesquisa na área veterinária existia apenas no Instituto Pasteur, como já mencionamos. A hipótese da centralização das atividades e da pesquisa até então desenvolvidas pelo instituto no Serviço Sanitário não parece suficiente para explicar o declínio.

A criação do curso médico em São Paulo explica o desinteresse dos cientistas em manterem os cursos, já a partir de 1911. A primeira escola de medicina absorveu como professores os drs. Ulisses Paranhos e Antonio Carini. Pouco mais tarde, em 1912, a Faculdade de Medicina e Cirurgia de São Paulo foi criada por Francisco de Paula Rodrigues Alves, sua implantação ficando sob a responsabilidade do dr. Arnaldo Vieira de Carvalho. Carini irá lecionar microbiologia e imunologia de 1916 a $1920 .{ }^{\circ}$

$O$ que parece ter existido foi uma dificuldade no relacionamento entre o Serviço Sanitário e o Instituto Pasteur; ou seja, não se conseguiu criar um vínculo cooperativo entre estas instituições, o que inviabilizou a manutenção do Instituto Pasteur como instituição sem fins lucrativos.

Entre 1891-93, a estruturação do Serviço Sanitário de São Paulo e a definição de uma política de saúde pública começaram a ser idealizadas, montadas e, por fim, consolidadas no primeiro Código 
Sanitário do Estado de 1894. Em 1896, a reforma sanitária reestruturou o Serviço Sanitário de forma a criar um conjunto mais articulado de instituições voltadas para promover ações sanitárias no combate às epidemias, o Serviço Geral de Desinfecções, para estudar e produzir diagnósticos com base na análise bacteriológica, o Instituto Bacteriológico (mais tarde Adolfo Lutz), para fiscalizar a comercialização de alimentos, as farmácias etc., o Laboratório de Análises Químicas e Bromatológicas, para produzir soros, vacinas e preparados químicos, o Instituto Vacinogênico, o Laboratório Químico e Farmacêutico e o Instituto Butantã, este último incorporado à estrutura do Serviço Sanitário em 1899, para elaborar as estatísticas demográfico-sanitárias, a Seção de Estatística Demográfico-Sanitária e, para executar e definir a política sanitária, a Diretoria do Serviço Sanitário. Até 1911, o Serviço Sanitário apresentará esta estrutura (Ribeiro, 1993).

Embora o Serviço Sanitário fosse bastante abrangente, ele não conseguia cobrir todas as áreas da saúde pública. O tratamento da raiva, a produção da vacina anti-rábica, o diagnóstico da sífilis, dentre outros problemas de saúde pública, não eram cobertos. Portanto, a cooperação entre o Instituto Pasteur e o Serviço Sanitário poderia ter sido mais estreita nestas áreas. A capacitação do pessoal técnico e de cientistas para a realização dos serviços de saúde pública poderia ter sido realizada, dada a inexistência da Faculdade de Medicina, pelo Instituto Pasteur, que, por meio de cursos, formaria inspetores sanitários e pessoal de laboratório, técnicos e cientistas, fornecendo a qualificação científica e técnica apropriada ao pessoal do serviço sanitário. Entretanto, parece que, de forma geral, a cooperação não foi perseguida como objetivo da política de saúde pública. A única tentativa de estreitamento das relações de cooperação foi na fiscalização do comércio de alimentos e na análise da água utilizada no abastecimento, porém, nunca chegou a ser concretizada. Em troca da colaboração com o Serviço Sanitário e outros órgãos públicos, como, por exemplo, aqueles ligados à agricultura e pecuária, o Instituto Pasteur receberia subvenções públicas, que garantissem a sua manutenção, à semelhança do que ocorria com o Instituto Pasteur de Paris.

Infelizmente, tais cooperações não ocorreram e a manutenção do instituto ficou comprometida pela falta de recursos. As fontes de receita criadas pelas atividades do próprio instituto foram insuficientes e ele não pôde contar com uma subvenção pública condizente com suas necessidades.

A opção por se manter como uma instituição sem fins lucrativos para, desse modo, receber subvenções públicas, não o viabilizou. A saída para os pesquisadores, idealizada pelo dr. Ulisses Paranhos, foi começar a produzir profiláticos e pesquisa visando o lucro, 
com o qual, além de sustentar os cientistas, viabilizou financeiramente a pesquisa de novos produtos a serem lançados no mercado.

Encerravam-se as atividades do Instituto Pasteur de São Paulo. Seu patrimônio foi doado pelo seu conselho diretor ao estado de São Paulo, livre de qualquer condição, exceção à manutenção do nome. Durante quase três anos, após sua transferência para o Estado, o instituto permaneceu fechado e submetido a uma reforma. Apenas em 1918 foi reinaugurado para prestar serviço exclusivo de tratamento anti-rábico e produzir vacinas e soros anti-rábicos (Gambeta, 1982, p. 91). Ao passar para a esfera pública, o instituto perde seu caráter amplo de centro de pesquisa para se dedicar, com exclusividade, ao serviço contra a raiva, tornando-se semelhante aos institutos Pasteur existentes no país.

Aproveitando-se da experiência dos preparadores do instituto, o dr. Paranhos organizou a empresa Laboratório Paulista de Biologia (LPB), entrando no mercado de produtos farmacêuticos. O pequeno laboratório, criado em 1912, portanto quase quatro anos antes da incorporação do Instituto Pasteur ao Serviço Sanitário do estado de São Paulo, começou a fabricar produtos que o próprio instituto já produzia, passando a fazer concorrência ao instituto e a minar ainda mais suas parcas fontes de recursos. Diferentemente de Teixeira (1995, p. 122) e de Gambeta (1979), não vemos o laboratório criado por Paranhos como sucessor e nem herdeiro do Instituto Pasteur. Na verdade, o instituto passou para o Estado e seus cientistas deslocaram-se para outra esfera da atividade a iniciativa privada, visando lucros, e não mais a sociedade de caráter beneficente sem fins lucrativos como era concebido o instituto.

A criação do LPB é contemporânea ao processo de mudança que ocorre na indústria de produtos farmacêuticos e no mercado de medicamentos no país. Nos anos em torno da Primeira Guerra Mundial tem lugar a transformação na forma de organização da produção farmacêutica que se caracteriza pela formação de grandes laboratórios nacionais, os quais passam a produzir medicamentos de origem estrangeira e a processar matérias-primas básicas importadas. Em parte as empresas nacionais e as companhias estrangeiras aproveitam o momento de dificuldades e de escassez relativa no mercado, devido à guerra, para produzir internamente medicamentos antes importados já prontos para o consumo.

A partir da década de 1920, observa-se mais intensamente a entrada de grandes empresas estrangeiras da indústria químicofarmacêutica no mercado brasileiro, em especial no estado de São Paulo e no Distrito Federal. As empresas de produtos farmacêuticos passaram a investir no Brasil estimuladas pela 
7 Segundo Teixeira (1995), Rocha Lima, Arthur Moses, Henrique Aragão e Parreiras Hotta saíram do Instituto Oswaldo Cruz para fundar o Jaboratório particular Instituto Brasileiro de Microbiologia, que produzia soros e vacinas de uso veterinário e humano, e Olympio da Fonseca e Julio Muniz, também egressos do Instituto Oswaldo Cruz, criaram o Laboratório de Pesquisas Clínicas para fabricar diversos tipos de vacinas na década de 1920 . proteção à produção local oferecida pelas políticas governamentais (tarifas aduaneiras e outras) em relação à importação e pela disponibilidade local de matérias-primas. Dentre essas empresas estão a de origem francesa Rhodia, subsidiária das Usines Chimiques du Rhône-Poulenc, que entrou em 1919 e começou a produção químico-farmacêutica em 1921; a alemã Bayer, fabricante da aspirina, que entrou alguns anos antes da eclosão da Primeira Guerra Mundial; e os grandes laboratórios norte-americanos, Sydney-Ross Co, Merck \& Co e Parke-Davis (Suzigan e Szmrecsányi, 1994; Frenkel, 1978). Depois da Segunda Guerra Mundial, assistese a um processo de desnacionalização e a indústria segue uma tendência que irá configurar a estrutura que nós conhecemos hoje: forte presença das grandes empresas estrangeiras e numerosas pequenas empresas nacionais sem maior expressão no mercado.

Segundo Teixeira (1995), o caso do LPB não foi isolado, e outros pesquisadores de instituições científicas abandonariam seus empregos para fundar empresas destinadas à produção de medicamentos. Cita, como exemplo, o dr. Vital Brasil, que deixou o Instituto Butantã para fundar um laboratório, o Instituto Vital Brasil, na cidade de Niterói, em 1919. Este laboratório produziu diversos tipos de soros, também fabricados pelo Butantã, e funcionou até 1956, quando foi encampado pelo governo do estado do Rio de Janeiro. Outro pesquisador do Butantã, Eduardo Vaz, fundou o Instituto Pinheiros, para produzir soros e vacinas e, mais tarde, começou a produzir uma pauta mais vasta de medicamentos. ${ }^{?}$

$\mathrm{Na}$ década de 1920, houve um movimento de êxodo de cientistas das instituições de pesquisa para a formação de laboratórios farmacêuticos. Não é mera coincidência que, em carta de 14 de abril de 1922, Monteiro Lobato aconselhe seu amigo Arthur Neiva, então ligado ao Instituto de Manguinhos, a não persistir no erro de continuar num posto onde não pode prosperar economicamente. Monteiro Lobato, então, aconselha ao amigo a tirar "partido do seu nome e dos seus conhecimentos montando um laboratório" e cita, como exemplo, nada mais nada menos do que "o Fontoura não vê como está próspero? ... e o Afrânio que só no Fontoura já tira mais de um conto por mês..." E conclui: "Em Manguinhos só lhe esperam trabalhos sem recompensas, aborrecimentos e nenhum futuro. Vindo trabalhar por conta própria em São Paulo, por exemplo, que clientela não teria! Era a fortuna, a liberdade e a mais deliciosa vitória porque provinda da iniciativa individual. Quer que eu estude com Fontoura um caminho para isso?" (Nunes, 1981, p. 28). Arhur Neiva não seguiu o conselho, porém, veio para São Paulo, chefiar a Comissão de Estudo e Debelação da Praga Cafeeira, a "comissão da broca do café", que irá originar o Instituto Biológico. 
Em 1960, quando $85 \%$ a $90 \%$ do mercado farmacêutico era dominado pelas empresas estrangeiras e nenhuma empresa nacional encontrava-se entre os seis maiores laboratórios classificados como 'superempresas', o Instituto Pinheiros, o maior laboratório nacional, ocupava o $9^{\circ}$ lugar, quanto ao volume de vendas. Além do Instituto Pinheiros, apenas dois outros laboratórios nacionais estavam entre os 26 maiores do ramo: o Torres $\left(19^{\circ}\right)$, e o Medicamenta Fontoura $\left(20^{\circ}\right)$, ambos vendidos ao capital estrangeiro posteriormente (Paula, pp. 216-37).

Todas estas iniciativas concentraram-se nos anos da Primeira Guerra Mundial e década de 1920, indicando um movimento no sentido da fabricação interna de produtos antes importados e a tentativa de criação de uma indústria farmacêutica nacional, pois para muitos dos fundadores estava aberta a possibilidade de substituição de medicamentos importados por drogas nacionais. Essas iniciativas mostram que as condições já estavam maduras para o surgimento da indústria farmacêutica nacional, pois o país já contava com uma massa de cientistas capazes de conduzir esta indústria, que é uma das que mais exige a aproximação com a ciência e com o desenvolvimento da pesquisa científica. Por isso podemos caracterizar este período como aquele de florescimento da verdadeira indústria farmacêutica no país.

À guisa de conclusão, a trajetória do Instituto Pasteur assinala o papel desempenhado por esta instituição na promoção da ciência no Brasil. Sua atuação foi marcada como sendo a de um verdadeiro centro de pesquisa científica e aplicada, apesar do número reduzido de pesquisadores, produzindo conhecimento biológico, capacitando cientistas e técnicos e elaborando e aplicando técnicas de obtenção de medicamentos opoterápicos, soros e vacinas. Os percalços que acometem a produção da ciência numa sociedade de grandes desigualdades, onde a promoção da mesma tem escasso reconhecimento, marcaram seu descenso e o inviabilizaram. A incorporação ao Serviço Sanitário transformou-o na instituição prestadora de serviço de tratamento da raiva, de importância reconhecida, porém relativamente limitada no que diz respeito ao avanço da pesquisa científica. É, até mesmo, incorreto fazer qualquer comparação dada a natureza distinta dessas instituições homônimas - o Instituto Pasteur de 1903-16 e o Instituto Pasteur pós-1916. Porém, aqueles primeiros anos de dedicação intensa à ciência não foram em vão, deles resultaram pessoas capacitadas, que se deslocaram para outra atividade produtiva, levando as bases científicas e técnicas na área médicofarmacêutica, e contribuíram para o surgimento da moderna indústria farmacêutica no país. 
RIBEIRO, M. A. R.: 'Lições para a história das ciências no Brasil: Instituto Pasteur de São Paulo'. História, Ciências, Satide - Manguinbos, III (3):467-484, nov. 1996-fev. 1997.

Este artigo pretende mostrar a importância e o papel do Instituto Pasteur de São Paulo (1903-16) no desenvolvimento da ciência microbiológica no Brasil e no surgimento da indústria farmacêutica de capital nacional.

PALAVRAS-CHAVE: história das ciências, história econômica, saúde pública, indústria farmacêutica, São Paulo, Brasil.

\section{REFERÊNCIAS BIBLIOGRÁFICAS}

O Biológico nov. 1984

Dantes, Maria

Amélia Mascarenhas 1979-80

Faculdade de

Medicina da USP 1991

Frenkel, Jacob et alii. 1978

Gambeta,

Wilson Roberto dez.-mar. 1982

Gambeta, Wilson Roberto; Camelet, Esther L. B.; Souza, Luiza T. N. e Azevedo, Murilo $P$.

1979

Lacaz, Carlos da Silva 1989

Nadai, E. 1981

Nunes, Cassiano 1981

Paula, Maria

Carlota de Souza 1991

Queiroz, Mauricio

Vinhas de $e$

Evans, Peter 1977

Rheinboldt, Heinrich 1956

Ribeiro, Maria Alice Rosa 1993
São Paulo, ano 43, n 11 e 12, 1977 e v. 50, Suplemento Comemorativo.

'Institutos de Pesquisa Científica no Brasil'. Em M. G. Ferri e S. Motoyama (orgs.), História das ciências no Brasil. São Paulo, Epu/Edusp, pp. 342-80.

Centenário de criação da Faculdade de Medicina da Universidade de São Paulo 1891-1991. Lei $n^{2} 19$ de 24 de novembro de 1891. São Paulo.

Tecnologia e competição na indístria farmacêtutica.

Rio de Janeiro, Finep. (mimeo.)

'Ciência e indústria farmacêutica. São Paulo. Primeira República' Estudos Econômicos, v. 12, n² 3, pp. 87-98.

Instituto Pasteur de Sâo Paulo - 75 anos de atividade: 1903-78. São Paulo, Imprensa Oficial do Estado.

Médicos italianos em São Paulo: trajetória em busca de uma nova pátria. São Paulo, Aquarela.

A ideologia do progresso e o ensino superior. Tese de doutoramento, São Paulo, USP/FFLCH.

O patriotismo dificil: a correspondência entre Monteiro Lobato e Artur Neiva. São Paulo, s. ed.

Oportunidades e entraves ao desenvolvimento tecnológico no Brasil: as experiências da indístria aeronáutica e indístria farmacêutica. Tese de doutoramento, USP/FFLCH, São Paulo.

'Um delicado equilibrio: o capital internacional e o local na industrialização brasileira'.

Caderno Cebrap, $\mathrm{n}^{\circ}$ 28, São Paulo, Brasiliense, pp. 8-33.

'A química no Brasil'. Em F. Azevedo (org.), As ciências no Brasil. São Paulo, Melhoramentos.

História sem fim... inventário da saúde pública: São Paulo, 1880-1930. São Paulo, Edunesp. 
MARIA ALICE ROSA RIBEIRO

Teixeira, Luiz Antonio 1995

Suzigan, Wilson e

Szmrecsányi,Tamás 1994
Ciência e saúde na terra dos bandeirantes: uma trajetória do Instituto

Pasteur de São Paulo no periodo 1903-16.

Rio de Janeiro, Fiocruz.

Os investimentos estrangeiros no inicio da industrialização do Brasil.

Textos para Discussão no 33, Campinas, Instituto de Economia/Unicamp.

Recebido para publicação em setembro de 1996. 